\title{
HISTORY \\ Our surgical heritage: the role of the Department of Paediatric Surgery in the development of paediatric surgery in Cape Town, in Africa, and around the world
}

\author{
Heinz Rode, Alastair J W Millar
}

The Department of Paediatric Surgery at the University of Cape Town has made a remarkable contribution to the academic body of knowledge of Paediatric Surgery both in South Africa and around the world. It has played a key role in the development of the specialty in South Africa and through the South African diaspora has trained many paediatric surgeons who have made their mark internationally. More recently it has become a major focus of teaching and training for African paediatric surgeons. This article traces this legacy through its origins in the early 1920s to its current prominent position in the world paediatric surgical community.

S Afr Med J 2012;102(6):409-411.
Public awareness in South Africa (SA) regarding the special needs of sick children was awakened by the human tragedy and suffering that followed in the wake of World War I, which claimed an estimated 16 million lives, and the post-war influenza epidemic that swept the world in 1918, killing an estimated 50 million. ${ }^{1}$ The socio-economic problems of that time and the fact that there was no separate provision for children in various government hospitals were the driving forces behind endeavours to give children a rightful place. The establishment of children's hospitals reflected the work of early pioneers, mainly socially conscious women, who overcame prejudice and resistance from provincial authorities and from those accustomed to catering only to the needs of adults. By succeeding in their efforts they underscored the importance of Paediatrics, and subsequently of Paediatric Surgery (PS), as a major discipline.

The development of PS in SA was greatly influenced by 4 children's hospitals that were built as free-standing and independent centres, utilising old military barracks or as children's pavilions within adult hospitals. These were the Transvaal Memorial Hospital for Children (opened 1923, closed 1978), the Children's Memorial Hospital, Durban (opened 1931, closed 1990), the Red Cross War Memorial Children's Hospital (RCWMCH; opened 1956) and the Pretoria Children's Hospital (opened 1947, closed 1987). These facilities were committed to providing active, high-quality, cost-effective, primary, preventative and specialised care to children. ${ }^{2}$

Heinz Rode, Emeritus Professor of Paediatric Surgery, commenced paediatric surgical training at Red Cross War Memorial Children's Hospital (RCWMCH) in 1975 and has been on the staff ever since. He was appointed to the Charles F M Saint Chair of Paediatric Surgery in 1996 and retired in 2006. He has maintained an interest in burns and currently is Head of the Burns Unit at the RCWMCH. Alastair I W Millar, Charles F M Saint Professor of Paediatric Surgery, University of Cape Town and RCWMCH, qualified at UCT and trained in paediatrics at Groote Schuur Hospital and RCWMCH before undertaking surgical training in the UK and Australia. He was consultant paediatric surgeon at RCWMCH (1984 - 2003) and Professor of Paediatric Transplantation, Birmingham Children's Hospital (2004 - 2007).

\section{Paediatric surgery as a discipline}

The scope and practice of surgery have undergone considerable changes over the past century. They can be divided into 4 phases, in all of which the Department of Paediatric Surgery at the Department of Surgery at the University of Cape Town (UCT) and Groote Schuur Hospital (GSH) initially, and RCWMCH later, have played a leading role as centres for teaching, research and comprehensive patient care for over 70 years. $^{3-5}$

\section{The birth and infancy period}

Although the Cape Hospital Board was considering establishing a children's hospital from 1918, the erection of the first 22-bed children's hospital in Cape Town, the Dennis Buxton Memorial Hospital for Children in Claremont, was delayed until 1920. Thereafter nothing further was done apart from providing children's wards in Peninsula hospitals, of which Woodstock Hospital was the most prominent (where children were under the care of paediatricians Drs Louis Leipoldt, Dowie Dunn and Wolf Rabkin). In those early days surgeons were regarded as mere technicians, the senior paediatricians remaining firmly in control of diagnosis, as well as pre- and postoperative care. Also, senior general surgeons were scathing in their comments if a young enthusiast chose to concentrate on PS and treat conditions such as intussusception and pyloric stenosis. Dominant surgical conditions in the children's general wards in GSH were sepsis, peritonitis, tuberculosis of bone and joints, chronic osteitis, bowel obstruction, empyema, burns, lymphadenopathy, urological conditions and ear, nose and throat diseases, with rare congenital abnormalities that carried a generally dismal prognosis. ${ }^{6}$

Advances in surgery and anaesthesia during World War II (WW2) and the return of medical ex-serviceman had a profound influence on surgical practice: operative techniques had become gentler, operative mortality less and outcomes vastly improved. Dr J H (Jannie) Louw, a general surgeon by training, had his interest in PS awakened in 1944 by the death, due to intestinal atresia at 11 days, of his first-born son. $\mathrm{He}$ had met Mr David Waterston, one of the pioneers of PS, from the Great Ormond Street Hospital for Sick Children (GOSH), London, while on active service in North Africa during WW2. This chance meeting led to a Dominion Fellowship at the GOSH in 1950/1 where Louw retrospectively investigated all infants born with intestinal atresia from 1925 , and among whom he documented a greater than $95 \%$ mortality.

In 1948 Dr Louw was put in charge of all 28 general surgery beds for children at GSH, consolidated into a paediatric surgical department in 
1952. Professor Jannie Louw came to be regarded as the Father of PS in SA. When RCWMCH opened in 1956,50\% of the beds were allocated to surgical patients, an acknowledgement of the new philosophy and the urgent need for such facilities.

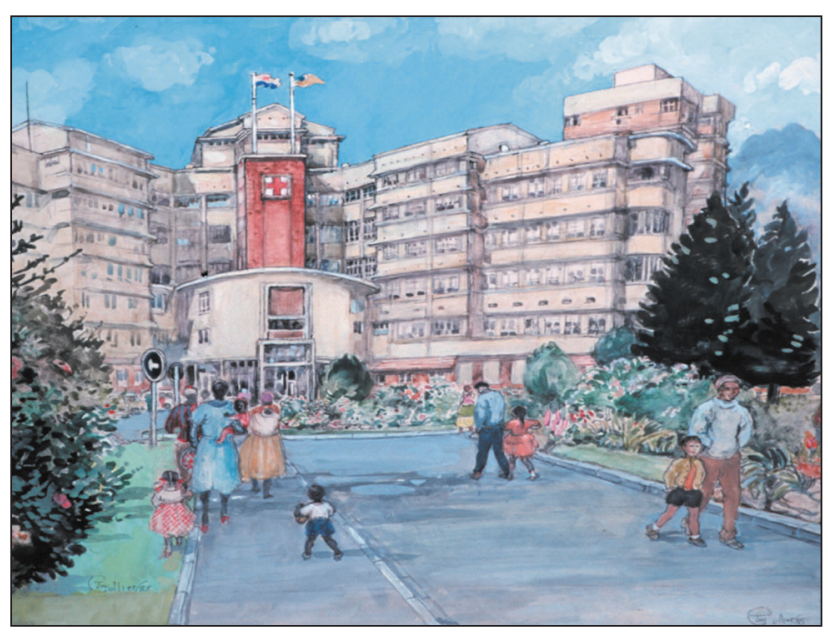

Red Cross War Memorial Children's Hospital - circa 1987. The artist Joy Collier has depicted the right profile of the future development of the complex.

\section{The second period}

Significant progress in medical sciences was made during the early 1950s to the mid-1960s. The development of new surgical techniques and the increasing interest of surgeons who chose to specialise in PS were responsible for the survival of children with conditions that previously had proved universally fatal. The nearly $100 \%$ mortality for serious congenital defects was reduced to less than $20 \% .{ }^{8}$ In 1961 another milestone was reached when a special intensive care unit of 8 beds was opened at RCWMCH.

Sidney Cywes was the first surgeon in SA to restrict his practice entirely to the surgical care of children and in 1975 he succeeded Professor Louw as Head of PS and was appointed to the newly established Charles F M Saint Chair of PS at UCT. Two other surgeons, Arnold Katz and Ryno van der Riet, both in private practice, took on the care of children with osteitis and thermal injuries as part-time staff of RCWMCH.

\section{The third period}

This was the era of steady recognition of PS as a subspecialty, requiring 2 years of training following attainment of the general surgical fellowship, culminating in registration by the then South African Medical and Dental Council in 1984. During this period rapid advances were made in diagnosis, investigation, management, prognosis and understanding the causation of diseases. The emphasis was increasingly on the holistic care of the surgically ill child, in particular newborn infants and patients undergoing major surgical procedures. Disease patterns also changed and the volume of work rapidly increased. It was also during this period that surgical wards and outpatients clinics became progressively racially integrated. Theatres had never been segregated and from 1980 the intensive care units (ICUs) were amalgamated.

Significant developments and expansion occurred from the mid-1960s to the beginning of the new millennium, with the establishment of a neonatal surgical unit with neonatal ICU (1976), a general ICU (1985), a designated trauma unit (1984), and solid organ transplantation facilities: kidney (1968), liver (1987) and heart (1990). The Burns Unit developed into a large and successful facility, treating over 900 burned children annually. The Child
Accident Prevention Foundation of Southern Africa was established in 1978 to raise awareness and focus attention on the devastating effect of the trauma epidemic on children. A day-case surgical unit was opened in the 1960s and was consolidated into a Day Surgery Unit in 2000. Further consultant PS appointments were made and subspecialty services were developed. Furthermore part-time staff made significant contributions to development and function of the department through assistance with teaching and patient care. The rapid progress in PS also led to the establishment of dedicated paediatric anaesthetists, paediatric surgical nurses and stomatherapists.

\section{The fourth period}

The period from 2006 onwards is characterised by the modern technological world of digitalised theatres, minimally invasive surgery and advanced training in a skills laboratory. In 2007 PS came of age when it was registered as a full specialty in its own right with the Health Professions Council of South Africa. The specialty now demands a 6-year training period in an accredited academic paediatric surgical department, with an exit examination and dissertation. Seven trainees have so far qualified as paediatric surgeons. Despite all modern developments to which the department has rapidly adapted, PS is faced with challenges posed by the large number of sick children, the disease patterns specific to this region, late presentations, advanced pathology and financial constraints.

\section{Scientific endeavours}

Paediatric surgeons recognised from the beginning that they were confronted not only by common diseases but also by the surgical pathologies that afflict children in the developing world. Scientific and research efforts were accordingly directed towards finding solutions to these problems.

The first major contribution dealt with the clinical and experimental work on intestinal atresia, which was internationally acclaimed and paved the way for intra-uterine fetal surgery. ${ }^{7}$ Other interests have been in the fields of trauma, congenital abnormalities, Hirschsprung's disease, oncology, caustic injuries, ano-rectal abnormalities, conjoined twins, thermal injuries, liver and renal transplantation and diseases unique to the developing world, such as parasitic infections and surgical infections of soft tissues and bone. Southern Africa has a high incidence of conjoined twins, 50 sets of whom have been treated at RCWMCH since 1964, representing one of the largest single-centre experiences in the world. ${ }^{9}$

RCWMCH's exceptional contribution to PS is underscored by the large number of overseas surgeons seeking postgraduate training in the department. Since its opening in 1956, it has hosted 27 trainees from England/Europe, 23 from sub-Saharan Africa, 7 from Israel, 6 from the Americas and 3 from the Far East. More than 90 surgical fellows have trained in the department over 5 decades, many of whom have filled Chairs of PS or became heads of departments in their respective countries (including SA, Canada, Argentina, Brazil, Paraguay, the USA, England, Northern Ireland, Australia, Iran, Taiwan, Turkey, Israel and several countries in Europe). Many trainees have made major contributions, particularly in the fields of neonatal surgery and oncology while in SA or upon return to their country of origin. Since the early 1990s postgraduate trainees from sub-Saharan countries (Cameroon, Cote d'Ivoire, Ethiopia, Gabon, Kenya, Zambia, Malawi, Nigeria, Tanzania, Madagascar and Uganda) have undergone training at RCWMH, returning home often to become the only trained paediatric surgeon in their home country.

Paediatric surgeons from RCWMCH have received numerous prestigious honours from national and international societies and 


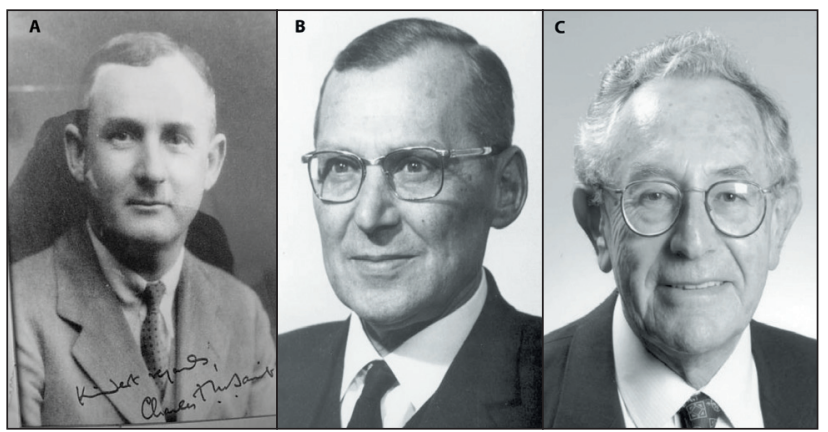

Pioneers of paediatric surgery in South Africa. (A) Professor Charles F M Saint, first Professor of Surgery, University of Cape Town (UCT), 1920 - 1946. (B) Professor J H Louw, the Father of Paediatric Surgery, Professor of Surgery at UCT, 1955 - 1980, and Head of Surgery at Red Cross War Memorial Children's Hospital, 1955 - 1975. (C) Professor Sidney Cywes, first Charles F M Saint Professor of Paediatric Surgery, UCT, 1975 - 1996.

colleges, and have served as international visiting professors, as members of executive committees of international organisations and as presidents and secretaries of the British Association of Paediatric Surgeons (BAPS) and the World Federation of Associations of Paediatric Surgeons; they were the driving force behind the establishment of the South African Association of Paediatric Surgeons and the Pan African Paediatric Surgical Association.

Professor Sidney Cywes was only the second paediatric surgeon in the world to receive an Honorary Fellowship of the College of Surgeons of America. In addition he was also awarded an Honorary Doctorate of Science in Medicine from UCT. A J W Millar was awarded the coveted Denis Browne Gold Medal from the British Association of Paediatric Surgeons, for outstanding contributions to paediatric surgery; Professor A B van As received the prestigious Micheal van Flooten Medal from the Dutch Surgical Society, and Professor H Rode was honoured with the Zora Janzekovic Golden Razor Award in recognition for outstanding contributions to paediatric surgical burn care.

Much of the history of PS in SA is reflected in the writings of the paediatric surgeons from RCWMCH: J H Louw, Sid Cywes, Mike Davies, Heinz Rode, Alastair Millar, Rob Brown and Alp Numanoglu, and of the many who spent their formative years in the shadow of Table Mountain. Collectively they have contributed 4 textbooks, over 150 book chapters and more than 1000 peer-reviewed publications to the literature on PS.

\section{What about the future?}

Working and living in Africa calls for a particular dedication to serve the children of this country and this continent, a commitment which these children desperately need and so richly deserve.

For more than half a century many idealistic men and women have fought for the interests of children. UCT celebrates their philosophy, their achievements and their teachings. It is incumbent upon the current and future generations to continue to build on the solid foundations that have been laid by our forebears.

South African UCT Paediatric Surgical Alumni who have made significant national and international contributions here and overseas include Barry Shandling (1957 - 1961), Hospital for Sick Children, Toronto, Canada; Johan Jacobs (1961) Pretoria; John Beck (1972 1973), Leeds, UK; David Lloyd (1970 - 1972), University of Natal, Durban, Professor of Paediatric Surgery, Liverpool, UK (1988 2004), and President of BAPS (2000 - 2002); Don Nuss (1971 1972), Norfolk, Virginia, USA, who described the Nuss procedure for pectus excavatum; Mike Davies (1969 - 1983), Professor of Paediatric Surgery, University of the Witwatersrand (1984 - 2004); Sam Moore (1986 - 1992), Professor of Paediatric Surgery at the University of Stellenbosch (1992 - present); Kokila Lakhoo (1990 1992), Baragwanath Hospital, Johannesburg and Radcliffe Infirmary, Oxford, UK; Colin Lazarus (1992 - 1993), Head of Eastern Cape Paediatric Surgical Services and Professor of Paediatric Surgery, UNITRA; Janet McNally (1995 - 1996), Bristol, UK; Esme le Grange (1999 - 2002), Bloemfontein, Head of Department of Paediatric Surgery (2003 - present); and Jonathan Karpelowsky (2006 - 2009), Sydney, Australia.

\footnotetext{
1. Wikipedia. The 1918 influenza epidemic. http://en.wikipedia.org/wiki/1918_flu_pandemic (accessed 5 February 2012).

2. Rode H, Davies MRQ, Berg A. The rise and fall of children's hospitals in South Africa. S Afr Med I 2006;96(9):849-853.

3. Louw JH. Paediatric Surgery - has it arrived? S Afr Med J 1967;41:1047-1050.

4. Cywes S, Millar AJW, Rode H. From a 'Louw' beginning...pediatric surgery in South Africa. J Pediatr Cywes S, Millar AJW, Rode
Surg 2003;38(7):44-47.

5. Louw JH. The first two decades of the Red Cross War Memorial Children's Hospital. S Afr Med I 1976;50(27):1037-1047

6. Louw JH. In the Shadow of Table Mountain. Cape Town: C Struik, 1969.

7. Louw JH, Barnard CN. Congenital intestinal atresia: observations on its origin. Lancet 1955;269(6899):10651067

Red Cross War Memorial Children’s Hospital (RCWMCH). Annual Report. Cape Town: RCWMCH, 1961.

9. Rode H, Fieggen AG, Brown RA, et al. Four decades of conjoined twins at Red Cross Children's Hospital - lessons learned. S Afr Med J 2006;96(9):931-940.
}

Accepted 6 March 2012. 